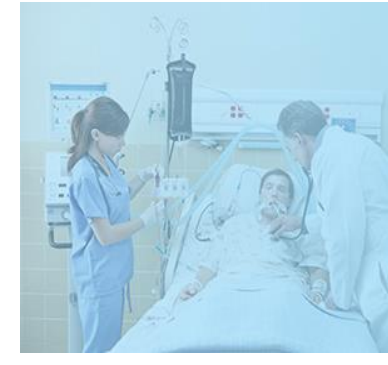

E-ISSN: $2663-2268$

P-ISSN: 2663-225X

IJARMSN 2021; 3(1): 44-47

Received: 28-11-2020

Accepted: 30-12-2020

R Golda Sahaya Rani

Professor, Medical Surgical

Nursing, Shri Sathya Sai

College of Nursing, Tamil

Nadu, India
Corresponding Author: R Golda Sahaya Rani

Professor, Medical Surgical

Nursing, Shri Sathya Sai

College of Nursing, Tamil

Nadu, India

\section{Dangerous popcorn lung: A risk of flavored e-cigarettes}

\author{
R Golda Sahaya Rani
}

DOI: https://doi.org/10.33545/surgicalnursing.2021.v3.i1a.61

\begin{abstract}
Popcorn lung is a rare type of permanent obstructive pulmonary disease that damages the bronchioles' tiny airways, making airflow difficult. Cough and shortness of breath are common symptoms of popcorn lung (bronchiolitis obliterans), which are similar to those experienced in persons with chronic obstructive pulmonary disease (COPD). Initially, there were signs and symptoms. Dyspnoea and wheezing are common indications and symptoms in the early stages. Fever or nocturnal sweats, as well as mucous membrane irritation. To determine an initial diagnosis, a complete history, lung function testing, chest X-rays, and CT scan are required. To treat respiratory symptoms and cell-mediated airway damage, corticosteroids, antibiotics, and oxygen may be employed. The disease has progressed to the point where lung transplantation may be required. Minimizing exposure to dangerous toxins and chemicals is a smart method to regulate and avoid popcorn lung. Make sure you're safe at work and quit smoking, as well as using e-cigarettes and vaping equipment.
\end{abstract}

Keywords: popcorn lung, bronchiolitis obliterans, airway obstruction, e-cigarettes

\section{Introduction}

Occupational airway diseases, such as bronchial asthma, acute and chronic bronchitis, byssin osis, and reactive airways dysfunction syndrome, are very common in workplace injuries [1]. While the prevalence rate of these syndromes is unknown, a few studies have suggested $t$ hat $15 \%$ of adults with Bronchial asthma have airway disease ${ }^{[2]}$. Because the illness relationship is unknown, the causes of these damages could include immunological sensitization, but they also entail irritant-mediated reactions to inhaled and nonallergic substances ${ }^{[3]}$. Bronchitis obliterans is also referred to as "popcorn lung." Bronchiolitis obliterans is a type of lung illness that is very rare. Popcorn lung is a common name for it. Scarring and inflammation are symptoms of popcorn lung ${ }^{[4]}$. Symptoms like as coughing, shortness of breath, and trouble breathing can occur when they are inflamed. This is a disorder that causes coughing and shortness of breath by damaging the lungs' tiniest airways. Breathing in a chemical used to flavour microwave popcorn can trigger it. Popcorn lung can also be caused by other substances or lung diseases ${ }^{[5]}$.

\section{Definition of popcorn lung disease}

Popcorn Lung Disease (Bronchiolitis obliterans) is an inflammatory disorder affecting the bronchioles, the smallest airways in the lungs. The scarring caused by swollen and irritated bronchioles creates airway obstructions. This sickness has no cure, and the damage is irreparable. (FIG-1). Respiratory infections, as well as breathing irritants such as nitrogen oxides, ammonia, welding fumes, or food flavouring fumes, can induce popcorn lung disease. Dry cough, wheezing, and shortness of breath are some of the symptoms ${ }^{[6,7]}$

\section{Incidence}

In the general population, popcorn lung disease (bronchiolitis obliterans) is uncommon. By ten years after a lung transplant, it affects roughly $75 \%$ of people, and up to $10 \%$ of patients who have received a bone marrow transplant from someone else ${ }^{[8]}$.

\section{Causes}

Exposure to certain dangerous chemicals, particles, and toxic gases present in microwave 
popcorn manufacturers and e-cigarettes can cause popcorn lung disease (Bronchiolitis obliterans). Other conditions can lead to popcorn lung as well. Some of these include:

- A respiratory illness, such as pneumonia or bronchitis

- A viral infection, such as respiratory syncytial virus (RSV)

- Collagen vascular diseases

- Drug reaction

A lung transplant (most common form of chronic lung transplant rejection) ${ }^{[9,10]}$.

\section{Pathophysiology}

Injury and inflammation in sub-epithelial cells and epithelial cells were the primary mechanisms. These epithelial cells have lost their ability to regenerate epithelial cells, which means they have lost their ability to rebuild tissue. This may cause cell development to accelerate and scarring to form. There are several disease mechanisms, including lymphocytic, fibrotic, and antibody-mediated. Although each route cause has its own set of symptoms, the end consequence is injury and inflammation, which results in scarred lung tissue. When scarred tissue forms, this is referred to as the expiration phase, and it is critical to breathe since the lungs are unable to release the air. This is known as air trapping, and it can be seen through imaging. Because the scared lung is not reversible, it may be difficult to recover over time, and it may develop a deadly path ${ }^{[11,12]}$.

\section{Clinical manifestation}

Shortness of breath, Dry cough, wheezing Exhaustion, flu-like illness with fever, unexplained fatigue, weight loss, eye, skin, mouth, or nose irritation, chest pain, and dizziness, if induced by chemical exposure ${ }^{[13]}$.

\section{Diagnostic evaluation}

The diagnostic examination of Popcorn lung begins with a thorough medical history, and several particular tests are required to confirm the disease's precise diagnosis. For the initial assessment, lung function tests such as (spirometry), chest X-rays, and CT scans should be performed.(FIG-2).To rule out Popcorn lung, a lung tissue biopsy, which generally required an open lung surgical operation, is required Popcorn lung (bronchiolitis obliterans). Because the illness can appear anywhere in lung tissue, it can be difficult for a pathologist to make an accurate diagnosis ${ }^{[14,15]}$.

\section{Treatment for popcorn lung}

The first step in treating popcorn lung is to eliminate any diacetyl exposure. To avoid chemical exposure, the face should be covered and a specific mask must be used. Depending on the circumstances, those individuals and the environment must be protected from diacetyl exposure ${ }^{[16]}$. This could assist to alleviate the discomfort. Steroids, oxygen supplementation, and antibiotics are used to treat patients who have been diagnosed with Popcorn Lung. However, the condition may advance to the stage that lung transplantation is essential $^{[17]}$.

\section{Nurses responsibility}

When dealing with a Popcorn lung patient, the role and responsibility of the nurse is to recognize the client's clinical manifestations, take immediate action, seek the systematic leadership of the nursing process, and collaborate with other health professionals to provide an effective patient care plan and psychological support.

- The Nurse should inquire about the patient's complete history of respiratory symptoms, their use of e-cigarettes or vaping in the previous months or years, the type of substance they have used, the location where they were purchased, the company name, and whether they have shared their e-cigarettes with neighbours, and this information should be reported to the Health Department.

- The client should be advised to quit smoking and vaping by the nurse. Permanent smoking cessation is beneficial in terms of lowering health risks.

- If the client develops signs and symptoms of respiratory difficulties such as chest pain, shortness of breath, cough, or wheezing, the Nurse should recommend them to go to the hospital and seek emergency treatment.

- Nurses' primary role is to have extensive knowledge of popcorn lung, such as nicotine-free products and the detrimental consequences of increasing nicotine.

- The nurse should explain that those who smoke or vape will have their cilia damaged as a result of the hair-like features of the lungs, making it difficult for air to enter the lungs. As a result of this consequence, the Corona virus will be able to reach the lungs more quickly $[18,19$, 20].

\section{Prevention}

- The initial incentive to convince those who are vaping to stop permanently is the precautionary steps to avoid lung harm.

- Avoiding settings where it is easier to inhale pollutants and chemicals is the most efficient strategy to avoid popcorn lung.

- You must use respiratory protection equipment when exposed to settings that may contain poisons or chemicals.

- Those who labour in other industries, such as construction, produce similar irritants such as dust, poison, and fumes. These workers are also at risk of developing minor airway disorders, which require immediate management in order to prevent significant impairment.

- If you have signs of popcorn lung, you should go to the emergency department immediately. If you get adequate treatment early enough, you can avoid further lung damage ${ }^{[21,22]}$.

\section{The interesting facts about popcorn lung}

- A physician revealed in the year 2000 that roughly eight former microwave-popcorn workers had been diagnosed with popcorn lung.

- Several cases of popcorn lung have been recorded by the CDC (Centers for Disease Control and Prevention) among personnel who work only at a microwave popcorn plant.

- Diacetyl's major function is as a flavouring agent for popcorn, and it's used to give it a buttery flavour.

- Those who have worked for a long time, have been physically exposed to diacetyl, and have inhaled the fumes for a long time are at risk of developing popcorn lung disease.

- Workers who are exposed to higher levels of nitrogen oxides are more likely to suffer acute respiratory failure, which is followed by non-cardiogenic pulmonary edoema and can lead to death.

- According to new studies, persons who do not smoke 
have the highest risk of developing popcorn lung ${ }^{[23,24]}$.

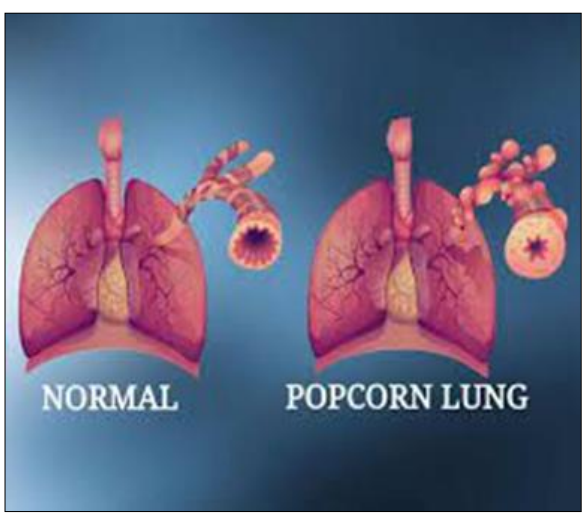

Fig 1: Picture reveals that normal lung and popcorn lung

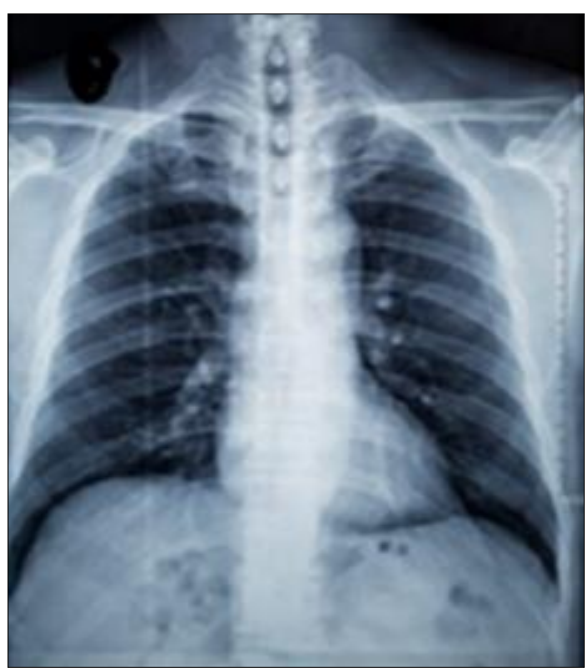

Fig 2: $\mathrm{X}$ ray shows the popcorn lung

\section{Conclusion}

Popcorn lung (Bronchiolitis obliterans) is an inflammatory and fibrotic condition characterized by total or partial blockage of the bronchiolar epithelium. Those who are exposed to flavouring compounds such as pentanedione, diketone, and diacetyl are at a higher risk of developing popcorn lung and other respiratory problems. The scarring of lung tissue caused by popcorn lung is irreversible. Stop smoking, exercise regularly, and eat a well-balanced diet to keep your lungs healthy.

\section{References}

1. Joseph Mulligan, Paul Deitrick, Shelia Weaver, Farnaz Valei, Allen Fred Fielding. Popcorn Lung and ECigarettes the Risk of Post OP Anesthesia Complications, J Pulm Med Respir Res 2018;4(1):1-4. DOI:10.24966/PMRR-0177/100019

2. NIOSH. Hazard evaluation and technical assistance report: International Bakers Services, South Bend, IN Cincinnati, OH. US Department of Health and Human Services, Public Health Service, Center for Disease Control, National Institute for Occupational Safety and Health, NIOSH Report No: HETA NIOSH HETA 1986;85:171-1710.

3. Romero S, Hernandez L, Gil J, Aranda I, Martin C, Sanchez-Paya J. Organizing pneumonia in textile printing workers: a clinical description. Eur Respir J 1998;11:26571.

4. Kreiss K, Gomaa A, Kullman G, Fedan K, Simes EJ,
Enright PL. Clinical bronchiolitis obliterans in workers at a microwave-popcorn plant. N Engl J Med 2002;347:330361.

5. Flowers JR, Clunie G, Burke M, Constant O. Bronchiolitis obliterans organizing pneumonia: the clinical and radiological features of seven cases and a review of the literature. Clin Radiol 1992;45:371-377.

6. Fedan JS, Dowdy JA, Fedan KB, Hubbs AF. Popcorn worker's lung: In vitro exposure to diacetyl, an ingredient in microwave popcorn butter flavoring, increases reactivity to methacholine. Toxicol Appl Pharmacol 2006;215:17-22.

7. Simoes E, Maley R, Kreiss K, Malone J, Kanwal R. Fixed obstructive lung disease in workers at a microwave popcorn factory: Missouri, 2000-2002. MMWR Recomm Rep 2002;51:354-357.

8. Lockey JE, Hilbert TJ, Levin LP, Ryan PH, White KL et al. Airway obstruction related to diacetyl exposure at microwave popcorn production facilities. Eur Respir J 2009;34:63-71.

9. Boswell RT, McCunney RJ. Bronchiolitis obliterans from exposure to incinerator fly ash. J Occup Environ Med 1995;37:850-855.

10. Alleman T, Darcey DJ. Case report: bronchiolitis obliterans organizing pneumonia in a spice process technician. J Occup Environ Med 2002;44:215-216.

11. Boag AH, Colby TV, Fraire AE et al. The pathology of interstitial lung disease in nylon flock workers. Am J Surg Pathol 1999;23:1539-45.

12. Kovacic P, Cooksy AL. Electron transfer as a potential cause of diacetyl toxicity in popcorn lung disease. Rev Environ Contam Toxicol 2010;204:133-148.

13. Parmet AJ, Von Essen S. Rapidly progressive, fixed airway obstructive disease in popcorn workers: a new occupational pulmonary illness? J Occup Environ Med 2002;44:216-218.

14. Hankinson JL, Odencrantz JR, Fedan KB. Spirometric reference values from a sample of the general U.S. population. Am J Respir Crit Care Med 1999;159:179187.

15. Padley SP, Adler BD, Hansell DM, Muller NL. Bronchiolitis obliterans: high resolution CT findings and correlation with pulmonary function tests. Clin Radiol 1993;47:236-240.

16. Hubbs AF, Battelli LA, Goldsmith WT, Porter DW, Frazer D et al. Necrosis of nasal and airway epithelium in rats inhaling vapors of artificial butter flavoring. Toxicol Appl Pharmacol 2002;185:128-135.

17. Lockey J, Mckay R, Barth E, Dahlstern J, Baugham I. Bronchiolitis obliterans in the food flavoring manufacturing industry. Am J Respir Crit Care, Med 2002;165:Suppl:A461.

18. Larider Ruffin. The Roles of the Nurse During the Vaping Crisis, Iris Journal of Nursing \& Care 2019;2(3):1-2. DOI: 10.33552/IJNC.2019.02.000537

19. Akpinar-Elci $M$, Travis WD, Lynch DA, Kreiss K. Bronchiolitis Obliterans syndrome in popcorn production plant workers. Eur espir J 2004;24:298-302.

20. Duling MG, LeBouf RF, Cox-Ganser JM, Kreiss K, Martin SB Jr, Bailey RL. Environmental characterization of a coffee processing workplace with obliterative bronchiolitis in former workers. J Occup Environ Hyg 2016;13:770-81.

21. Barker AF, Bergeron A, Rom WN, Hertz MI. "Obliterative bronchiolitis". The New England Journal of 
Medicine 2014;370(19):1820-8.

doi:10.1056/NEJMra1204664.

22. Ravindran Chetambath. Popcorn lung - Report of a rare case and its significance in a coffee-growing district of Kerala, Lung India 2019;36(4):367-368. doi: 10.4103/lungindia.lungindia_441_18

23. Schachter EN. Popcorn worker's lung, The New England Journal of Medicine 2002;347(5):360-1. doi:10.1056/nejme020064.

24. Gonzalvo J, Constantine B, Shrock N, Vincent A. Electronic Nicotine Delivery Systems and a Suggested Approach to Vaping Cessation. AADE in Practice 2016;4(6):38-42. 